\title{
Corrigendum: Nogo-A-deficient transgenic rats show deficits in higher cognitive functions, decreased anxiety, and altered circadian activity patterns
}

\author{
Tomas Petrasek ${ }^{1,2 *}$, Iva Prokopova ${ }^{1}$, Martin Sladek ${ }^{3}$, Kamila Weissova ${ }^{3}$, Iveta Vojtechova ${ }^{1}$, \\ Štěpán Bahník ${ }^{1,4}$, Anna Zemanova ${ }^{1}$, Kai Schonig ${ }^{5}$, Stefan Berger ${ }^{5}$, Bjorn Tews ${ }^{6,7}$, Dusan Bartsch ${ }^{5}$, \\ Martin E. Schwab ${ }^{6}$, Alena Sumova ${ }^{3}$ and Ales Stuchlik ${ }^{1 *}$ \\ ${ }^{1}$ Department of Neurophysiology of Memory, Institute of Physiology, Academy of Sciences of the Czech Republic, Prague, Czech Republic \\ ${ }^{2}$ First Faculty of Medicine, Charles University in Prague, Prague, Czech Republic \\ ${ }^{3}$ Department of Neurohumoral Regulations, Institute of Physiology, Academy of Sciences of the Czech Republic, Prague, Czech Republic \\ ${ }^{4}$ Department of Psychology II, Social Psychology, University of Würzburg, Würzburg, Germany \\ ${ }^{5}$ Department of Molecular Biology, Central Institute of Mental Health, Mannheim, Germany \\ ${ }^{6}$ Brain Research Institute, University of Zürich, and Department of Biology, ETH Zürich, Zürich, Switzerland \\ ${ }^{7}$ Division of Molecular Mechanisms of Tumor Invasion, German Cancer Research Center, Heidelberg, Germany \\ *Correspondence: disworlds@gmail.com; stuchlik@biomed.cas.cz
}

Edited and reviewed by:

Tomiki Sumiyoshi, National Center of Neurology and Psychiatry, Japan

Keywords: corrigendum, Nogo-A, behavior, animal, circadian rhythm, memory, navigation, anxiety

A corrigendum on

Nogo-A-deficient transgenic rats show deficits in higher cognitive functions, decreased anxiety, and altered circadian activity patterns

by Petrasek, T., Prokopova, I., Sladek, M., Weissova, K., Vojtechova, I., Bahník, S., Zemanova, A., Schönig, K., Berger, S., Tews, B., Bartsch, D., Schwab, M. E., Sumova, A., and Stuchlik, A. (2014). Front. Behav. Neurosci. 8:90. doi: 10.3389/fnbeh.2014. 00090

In the paper by Petrasek et al., a mistake was made in the Acknowledgments Section. The corrected Acknowledgments follow:

\section{ACKNOWLEDGMENTS}

This work was funded mainly by GAUK grant 365911 (awarded to Tomas Petrasek, which supported Tomas Petrasek, Iva
Prokopova, Štěpán Bahník, and Iveta Vojtechova), GACR P304/12/G069 (awarded to Ladislav Vyklicky, which supported Martin Sladek, Kamila Weissova, Alena Sumova, Tomas Petrasek, and Ales Stuchlik) and GACR 14-03627S (awarded to Ales Stuchlik, which supported Tomas Petrasek, Iveta Vojtechova, and Ales Stuchlik). Additional support came from IGA MZ CR NT13386 and AVCR M200111204 (awarded to Ales Stuchlik).

Support for foreign partners was provided by grants from the German Ministry for Education and Research (BMBF, 01GQ1003B), National Bernstein Network for Computational Neuroscience, HEALTH-F2-2007-201714 DEVANX (awarded to Dusan Bartsch) and the Grant Nr. 31-122527/1 (awarded to Martin E. Schwab). The work of Štěpán Bahník was partly supported by the Deutsche Forschungsgemeinschaft (DFG-RTG 1253/2).
Conflict of Interest Statement: The authors declare that the research was conducted in the absence of any commercial or financial relationships that could be construed as a potential conflict of interest.

Received: 04 December 2014; accepted: 04 December 2014; published online: 23 December 2014

Citation: Petrasek T, Prokopova I, Sladek M, Weissova K, Vojtechova I, Bahník Š, Zemanova A, Schonig K, Berger S, Tews B, Bartsch D, Schwab ME, Sumova A and Stuchlik A (2014) Corrigendum: Nogo-A-deficient transgenic rats show deficits in higher cognitive functions, decreased anxiety, and altered circadian activity patterns. Front. Behav. Neurosci. 8:442. doi: 10.3389/ fnbeh.2014.00442

This article was submitted to the journal Frontiers in Behavioral Neuroscience.

Copyright (c) 2014 Petrasek, Prokopova, Sladek, Weissova, Vojtechova, Bahník, Zemanova, Schonig, Berger, Tews, Bartsch, Schwab, Sumova and Stuchlik. This is an open-access article distributed under the terms of the Creative Commons Attribution License (CC BY). The use, distribution or reproduction in other forums is permitted, provided the original author(s) or licensor are credited and that the original publication in this journal is cited, in accordance with accepted academic practice. No use, distribution or reproduction is permitted which does not comply with these terms. 